\title{
Ação de extratos de plantas medicinais sobre a motilidade do trato gastrointestinal
}

\author{
POTRICH, F.B.'; BAGGIO, C.H.'; FREITAS, C.S.1; MAYER, B.1; SANTOS, A.C.1; TWARDOWSCHY, A.'; \\ GUEDES, A. ${ }^{2}$, MARQUES, M.C.A. ${ }^{*}$ * \\ 1 Departamento de Farmacologia, Setor de Ciências Biológicas, Universidade Federal do Paraná, Caixa Postal \\ 19031, CEP: 81531-990, Curitiba-Brasil *mconsu@ufpr.br; '2 Departamento de Ciências Farmacêuticas, Centro \\ de Ciências da Saúde, Universidade Regional de Blumenau, Rua São Paulo, 2171, CEP: 89030-000, Blumenau- \\ Brasil
}

\begin{abstract}
RESUMO: Muitas plantas são utilizadas pela população para o tratamento e a cura de doenças. Entre elas encontram-se a Persea major Kopp, Piper mollicomum Kunth. e Serjania erecta Radlk. as quais são utilizadas para diversas enfermidades, inclusive para tratar distúrbios do trato gastrointestinal. O objetivo deste trabalho foi estudar os efeitos dos extratos dessas três plantas sobre a motilidade gastrointestinal. Camundongos Swiss foram tratados com os extratos pela via oral 1 hora antes da administração de uma solução semisólida de carboximetilcelulose $1,5 \%$ e vermelho de fenol $0,05 \%$ e, após 15 minutos, o esvaziamento gástrico e o trânsito intestinal avaliados. O extrato hidroalcoólico da P. major (100 a $1000 \mathrm{mg} \mathrm{Kg}^{-1}$, p.o.) e o extrato hidroalcoólico da P. mollicomum (100 e $300 \mathrm{mg} \mathrm{Kg}^{-1}$, p.o.) aumentaram o trânsito intestinal. No entanto, somente o extrato da $P$. major (100 e $300 \mathrm{mg} \mathrm{Kg}^{-1}$ ) também aumentou o esvaziamento gástrico. O extrato etanólico da S. erecta (100 a $1000 \mathrm{mg} \mathrm{Kg}^{-1}$, p.o.) não alterou a motilidade gastrointestinal. Estes resultados sugerem que a Persea major e a Piper mollicomum mereçam estudos mais aprofundados em busca de princípios ativos ou matéria vegetal efetiva para 0 tratamento de distúrbios do trato gastrointestinal como a constipação.
\end{abstract}

Palavras-chave: plantas medicinais, distúrbios gastrointestinais, esvaziamento gástrico, trânsito intestinal

\begin{abstract}
Action of medicinal plant extracts on the gastrointestinal tract motility. Many plants are popularly used for the treatment and healing of diseases. The Persea major Kopp, Piper mollicomum Kunth. and Serjania erecta Radlk. are used in several illnesses, including the treatment of disorders of the gastrointestinal tract. The aim of this study was to evaluate the effects of the extracts of these plants on the gastrointestinal motility. Swiss mice were orally treated with extracts one hour before the administration of a semisolid solution of $1.5 \%$ carboxymethylcellulose and $0.05 \%$ phenol red. After 15 minutes, the gastric emptying and intestinal transit were determined. The hydroalcoholic extract of $P$. major (100 to $1000 \mathrm{mg} \mathrm{Kg}^{-1}$, p.o.) and the hydroalcoholic extract of $P$. mollicomum (100 and $300 \mathrm{mg} \mathrm{Kg}^{-1}$, p.o.) increased the intestinal transit. However, only the P. major extract (100 and $300 \mathrm{mg} \mathrm{Kg}^{-1}$ ) increased the gastric emptying. The ethanolic extract of $S$. erecta (100 to $1000 \mathrm{mg} \mathrm{Kg}^{-1}$, p.o.) did not alter the gastrointestinal motility. These results suggest that Persea major and Piper mollicomum can be of interest for further studies in the search of active principles or effective plant material for the treatment of disorders of the gastrointestinal tract, such as constipation.
\end{abstract}

Key words: medicinal plants, gastrointestinal disturbs, gastric emptying, intestinal transit

\section{INTRODUÇÃO}

A utilização de plantas no tratamento de enfermidades é relatada como sendo uma das práticas mais antigas da humanidade (Calixto, 2001). E por isso, acredita-se que as plantas medicinais foram testadas e homologadas através do seu uso prolongado, considerando-as eficazes e seguras, sem efeitos colaterais (Lapa et al., 2000). Neste contexto, são de extrema importância o estudo e a validação do uso de plantas medicinais que apresentem indicações populares. 
Dentre as plantas medicinais que são utilizadas popularmente para o tratamento de distúrbios do trato gastrointestinal estão a Persea major Kopp, Piper mollicomum Kunth. e Serjania erecta Radlk. (Peckolt \& Peckolt, 1888; Cosmo et al., 2007; Gomig et al., 2008). A Serjania erecta (Sapindaceae) é comumente conhecida como "cinco-folhas", "cipó-cinco-folhas" ou "retrato de teiú" e alguns estudos com diferentes espécies de Serjania e os compostos isolados demonstraram atividades analgésica, antiinflamatória tópica, antibacteriana, antifúngica e gastroprotetora (di Stasi et al., 1988; Ekabo et al., 1996; de Lima et al., 2006; Gomig et al., 2008; Castelo et al., 2009). As análises fitoquímicas do extrato hidroalcoólico de caules e folhas da $S$. erecta mostraram a presença de saponinas, flavonóides, triterpenóides, esteróides, taninos, catequinas, cumarinas e quinonas (Gomig et al., 2008). O "pau de Andrade" ou "abacateiro do mato", nomes populares da Persea major (Lauraceae), apresentou atividade analgésica, anti-edematogênica e gastroprotetora em estudos anteriores (Assis et al., 2003a; Assis et al., 2003b; Cosmo et al., 2007). Alguns constituintes químicos já identificados incluem ácidos graxos, aminoácidos, esteróides, triterpenos e taninos condensados (Maranho, 1998). A Piper mollicomum pertence à família Piperaceae e é conhecida como "jaborandi-manso" ou apenas "jaborandi" (Peckolt \& Peckolt, 1888). Poucos estudos fitoquímicos foram realizados com a $P$. mollicomum, entre eles a análise da composição do óleo essencial, mostrando que é composto principalmente por sesquiterpenos (Santos et al., 2001), e o isolamento de dois cromenos e uma chalcona com atividade antifúngica (Lago et al., 2007).

Tendo em conta essas informações, este trabalho teve como objetivo avaliar o efeito dos 3 extratos de plantas medicinais, que são utilizadas na medicina popular para o tratamento de distúrbios gastrointestinais, sobre a motilidade gastrointestinal de camundongos.

\section{MATERIAL E MÉTODO}

\section{Animais}

Foram utilizados camundongos Mus musculus, variedade Swiss, fêmeas e machos pesando entre $30-40 \mathrm{~g}$, provenientes do biotério do Setor de Ciências Biológicas da Universidade Federal do Paraná, onde foram mantidos em condição claro/escuro de 12 horas, com acesso a ração e água ad libitum. O protocolo experimental foi aprovado pelo Comitê de Ética em Experimentação Animal da Universidade Federal do Paraná, sob o número 192.

\section{Material Botânico}

O material vegetal (hastes e folhas) da Serjania erecta Radlk. foi coletado no município de Campo Mourão, PR, e secado a temperatura ambiente $\left(25-28^{\circ} \mathrm{C}\right)$ sobre controle de umidade (30$35 \%$ ). Exemplares estão depositados no Herbário Dr. Roberto Miguel Klein na FURB-SC com número 3369. O material vegetal $(135 \mathrm{~g})$ foi pulverizado a pó seco e extraído com etanol $70 \%$ durante 7 dias por maceração. $O$ extrato foi concentrado a temperatura reduzida e mantido no dissecador.

As cascas de Persea major (Ness) Kopp foram coletadas na EMBRAPA (Empresa Brasileira de Pesquisa Agropecuária), município de Colombo, $\mathrm{PR}$, e um exemplar está depositado e registrado sob o número 28382, no Herbário da Universidade Federal do Paraná. Realizou-se uma extração semicontínua, em aparelho de Soxhlet, onde foram utilizados $30 \mathrm{~g}$ do pó da casca de $P$. major e extraídas com aproximadamente $300 \mathrm{~mL}$ de etanol $70 \%$. As amostras foram liofilizadas, para obtenção do pó totalmente isento de água.

A coleta da Piper mollicomum Kunth. foi realizada no Parque Municipal São Francisco de Assis em Blumenau, SC, e estocado no Laboratório de Farmacognosia da FURB no qual foi realizado o procedimento para a obtenção do extrato bruto hidroalcoólico. As folhas foram secadas em temperatura ambiente por 2 dias e em estufa a $40^{\circ} \mathrm{C}$ por 24 horas. Após secagem, as folhas foram rasuradas para preparação do extrato hidroalcoólico. As folhas secas rasuradas $(362 \mathrm{~g})$ foram colocadas em maceração com solução hidroalcoólica (3 partes de álcool e 1 parte de água) sendo coberto pelo solvente protegido da luz e mantido por uma semana. O extrato obtido foi filtrado e concentrado em evaporador rotativo e mantido sob refrigeração.

\section{Determinação do trânsito intestinal e esvaziamento gástrico}

Os animais, em jejum de 6-8 h, foram divididos em oito grupos $(n=7)$ e tratados com veículo $\left(0,1 \mathrm{~mL} / 10 \mathrm{~g}\right.$, v.o.), atropina $\left(3 \mathrm{mg} \mathrm{Kg}^{-1}\right.$, s.c.), metoclopramida (30 $\mathrm{mg} \mathrm{Kg}^{-1}$, v.o.), neostigmina $\left(20 \mu \mathrm{Kgg}^{-1}\right.$, s.c.) e extratos (100 a $1000 \mathrm{mg} \mathrm{Kg}^{-1}$, v.o.). Após $1 \mathrm{~h}$, foi administrada, por via oral, uma solução semisólida de vermelho de fenol 0,05\% em carboximetilcelulose $1,5 \%$ e depois de $15 \mathrm{~min}$, os animais foram eutanasiados para a retirada do estômago e intestino delgado. As determinações foram baseadas no modelo de Suchitra et al. (2003), com algumas modificações. Na avaliação do esvaziamento gástrico, o estômago foi triturado com $7 \mathrm{~mL}$ de água destilada e o homogenato foi centrifugado a $1500 \mathrm{rpm}$ por $15 \mathrm{~min}$. Após a centrifugação, $600 \mu \mathrm{L}$ do sobrenadante foi misturado com $600 \mu \mathrm{L}$ de $\mathrm{NaOH} 0,025 \mathrm{~N}$ e lido

Rev. Bras. PI. Med., Campinas, v.16, n.3, supl. I, p.750-754, 2014. 
em espectrofotômetro a $560 \mathrm{~nm}$. O esvaziamento gástrico foi calculado de acordo com a fórmula $E G \%$ = 100 - [(Absorbância x 100)/Absorbância T0], onde o T0 representa a absorbância do vermelho de fenol recuperado de estômagos de animais eutanasiados 0 minutos após a administração do marcador. Para a avaliação do trânsito intestinal, o intestino delgado foi esticado e determinado o comprimento total do intestino e a distância percorrida pelo marcador (a última porção com no mínimo $1 \mathrm{~cm}$ ). $O$ trânsito intestinal foi calculado de acordo com a fórmula $\mathrm{TI} \%$ = distância percorrida pelo marcador $\times 100 /$ comprimento total do intestino.

\section{Análise Estatística}

Os dados foram representados como as médias \pm erro padrão das médias $(n=7)$. As diferenças entre as médias foram determinadas através da análise de variância (ANOVA) de uma via seguida do teste de Bonferroni. As análises foram realizadas usando o Programa para Windows, GraphPad Prism versão 5.0 (GraphPad Software, San Diego, EUA). Um valor de $p$ menor que 0,05 foi considerado significativo.

\section{RESULTADO}

O extrato bruto hidroalcoólico da Persea major (EHP), nas doses de 100, 300 e $1000 \mathrm{mg} \mathrm{Kg}^{-1}$, administrado por via oral, 1 hora antes do marcador, aumentou o trânsito intestinal em 64, 42 e 33\%, respectivamente, quando comparado com o grupo controle (C: $43,4 \pm 2,5 \%$ ). Os controles positivos do teste, a atropina (3 $\mathrm{mg} \mathrm{Kg}^{-1}$, s.c.) diminuiu o trânsito intestinal em $49 \%$ e a neostigmina $\left(20 \mathrm{\mu g} \mathrm{Kg}^{-1}\right.$, s.c) aumentou em $50 \%$ (Figura 1a). Além disso, o EHP também aumentou o esvaziamento gástrico em 32 e 43\% nas doses de 100 e $300 \mathrm{mg} \mathrm{Kg}^{-1}$, respectivamente, quando comparado com o grupo controle (C: $55,5 \pm 4,5 \%)$. A atropina (3 $\mathrm{mg} \mathrm{Kg}^{-1}$, s.c.) também diminuiu o esvaziamento gástrico em $58 \%$ enquanto que a metoclopramida (30 $\mathrm{mg} \mathrm{Kg}^{-1}$, v.o.) aumentou em 50\% (Figura 1b).

Em outro conjunto de experimentos, a administração oral do extrato hidroalcoólico da Piper mollicomum (EHPM), nas doses de $100 \mathrm{e}$ $300 \mathrm{mg} \mathrm{Kg}^{-1}$, aumentou o trânsito intestinal em $56 \mathrm{e}$ $41 \%$, respectivamente quando comparado ao grupo controle $(40,5 \pm 2,1 \%)$. De forma semelhante ao experimento anterior, a atropina diminuiu o trânsito intestinal em $44 \%$ e a neostigmina aumento em $63 \%$ (Figura 2a). No entanto, o esvaziamento gástrico não foi alterado nas doses testadas (100,300 e $1000 \mathrm{mg}$ $\left.\mathrm{Kg}^{-1}\right)$, quando comparado ao grupo controle (56,3 $\pm 5,6 \%)$. Os controles positivos do teste, atropina diminuiu o esvaziamento gástrico em $58 \%$ enquanto a metoclopramida aumentou em $45 \%$ (Figura $2 b$ ).

De forma contrária, o tratamento dos animais com o extrato bruto etanólico da Serjania erecta (EES), nas doses testadas de 100, 300 e $1000 \mathrm{mg} \mathrm{Kg}^{-1}$, não foi capaz de alterar o trânsito intestinal nem o esvaziamento gástrico quando comparado ao grupo controle (C: $43,6 \pm 1,4 \%$ e $53,5 \pm 5,5 \%$, respectivamente) (Figura $3 a$ e b). No entanto, os controles positivos, atropina reduziu o trânsito intestinal e o esvaziamento gástrico e a neostigmina aumentou o trânsito intestinal (Figura 3a e b).
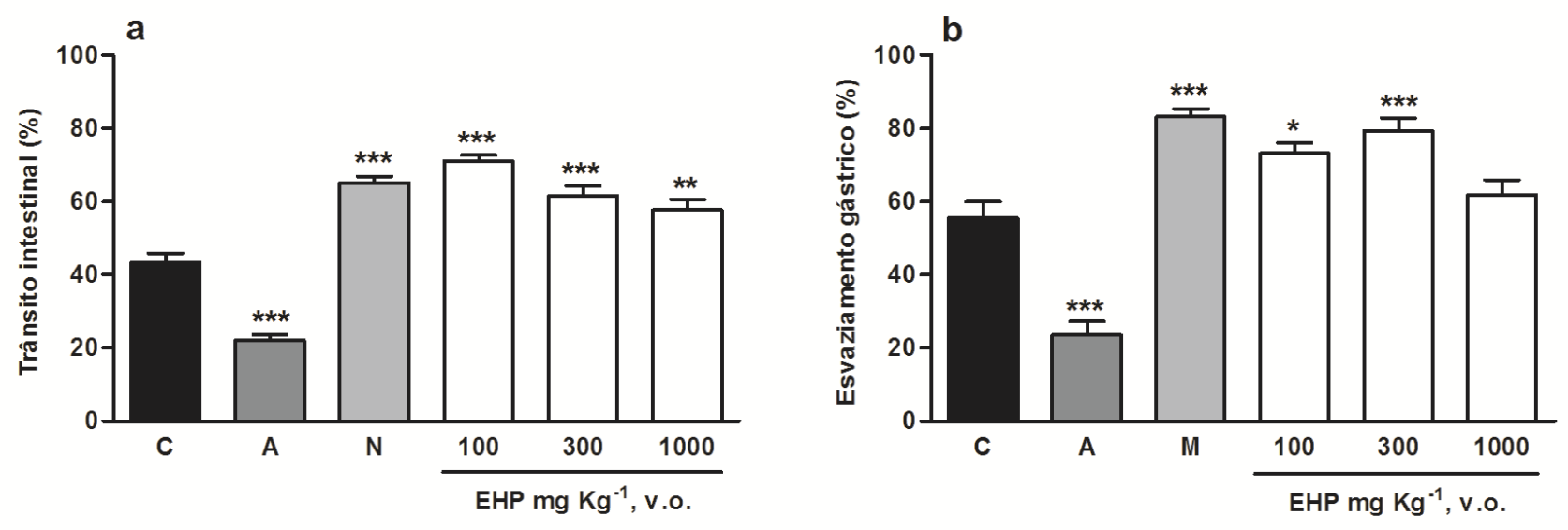

FIGURA 1. Efeito do extrato hidroalcoólico da Persea major (Ness) Kopp no trânsito intestinal (a) e esvaziamento gástrico (b). Os animais receberam veículo ( $C$, água $0,1 \mathrm{~mL} / 10 \mathrm{~g}, \mathrm{v.O}$ ), atropina ( $A=3 \mathrm{mg} \mathrm{Kg}^{-1}$, s.C), neostigmina ( $\mathrm{N}=20 \mu \mathrm{g} \mathrm{Kg}{ }^{-1}$, s.c), metoclopramida (30 $\mathrm{mg} \mathrm{Kg}^{-1}$, v.o.) e EHP (100, 300 e $1000 \mathrm{mg} \mathrm{Kg}^{-1}$, v.o.). Os resultados estão expressos como médias \pm erro padrão das médias $(n=7)$. A diferença entre os grupos foi determinada pela ANOVA de uma via seguida do teste de Bonferroni. ${ }^{*}$ Diferente do grupo controle para $\mathrm{P}<0,05,{ }^{* *}$ para $\mathrm{P}$ $<0,01 \mathrm{e}^{* * *}$ para $\mathrm{P}<0,001$.

Rev. Bras. PI. Med., Campinas, v.16, n.3, supl. I, p.750-754, 2014. 


\section{DISCUSSÃO}

Neste estudo, foram avaliados os efeitos de três extratos de plantas medicinais que possuem alguma indicação de uso popular para distúrbios do trato gastrointestinal, a Persea major (Nees) Kopp, a Piper mollicomum Kunth e a Serjania erecta Radlk (Peckolt \& Peckolt, 1888; Cosmo et al., 2007; Gomig et al., 2008). Apesar das indicações de uso, não há descrição na literatura de estudos que validem a ação destas plantas sobre a motilidade gastrointestinal.

O trato gastrointestinal é um potencial somatizador dos problemas emocionais vivenciados pelo homem, e isto está mais evidente nos dias atuais. Nas últimas décadas, distúrbios gastrointestinais tais como úlceras pépticas, refluxo

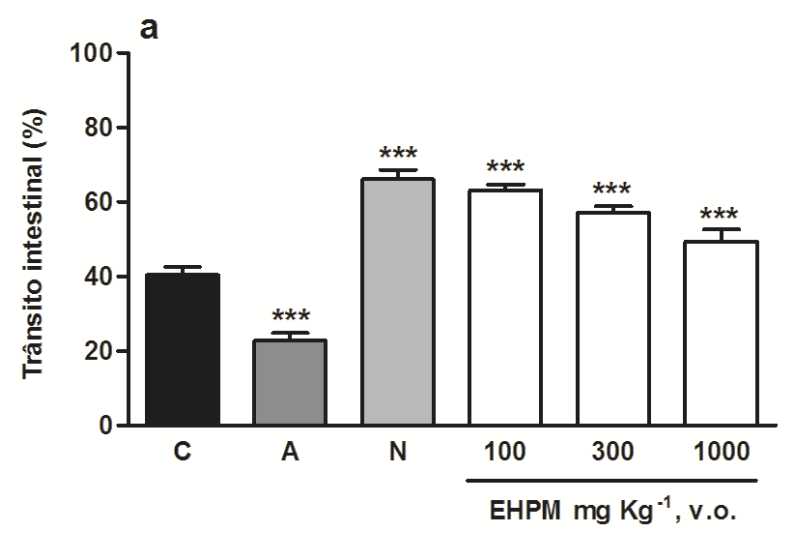

gastroesofágico, gastrite, doenças inflamatórias intestinais (doença de Crohn e colite ulcerativa) e constipação intestinal têm assumido altas proporções na população, tornando-se importantes focos de investigação experimental e clínica para a procura por novos tratamentos. Desde a antiguidade, os produtos naturais têm constituído importante fonte de agentes terapêuticos, sendo que diferentes fontes de substâncias naturais vêm sendo amplamente empregadas como estratégia para obtenção de novos compostos biologicamente ativos (Calixto, 2000).

Dentre as três plantas testadas neste estudo, somente o extrato hidroalcoólico da Persea major aumentou o esvaziamento gástrico e o trânsito intestinal, enquanto que o extrato hidroalcoólico

FIGURA 2. Efeito do extrato hidroalcoólico da Piper mollicomum Kunth. no trânsito intestinal (a) e esvaziamento gástrico (b). Os animais receberam veículo ( $C$, água $0,1 \mathrm{~mL} / 10 \mathrm{~g}, \mathrm{v} . \mathrm{O})$, atropina ( $A=3 \mathrm{mg} \mathrm{Kg}^{-1}$, s.C), neostigmina ( $\mathrm{N}=20 \mu \mathrm{g} \mathrm{Kg}^{-1}$, s.c), metoclopramida (30 mg Kg-1, v.o.) e EHPM (100, 300 e $1000 \mathrm{mg} \mathrm{Kg}^{-1}$, v.o.). Os resultados estão expressos como médias \pm erro padrão das médias $(n=7)$. A diferença entre os grupos foi determinada pela ANOVA de uma via seguida do teste de Bonferroni. ${ }^{* * *}$ Diferente do grupo controle para $\mathrm{P}<0,001$.
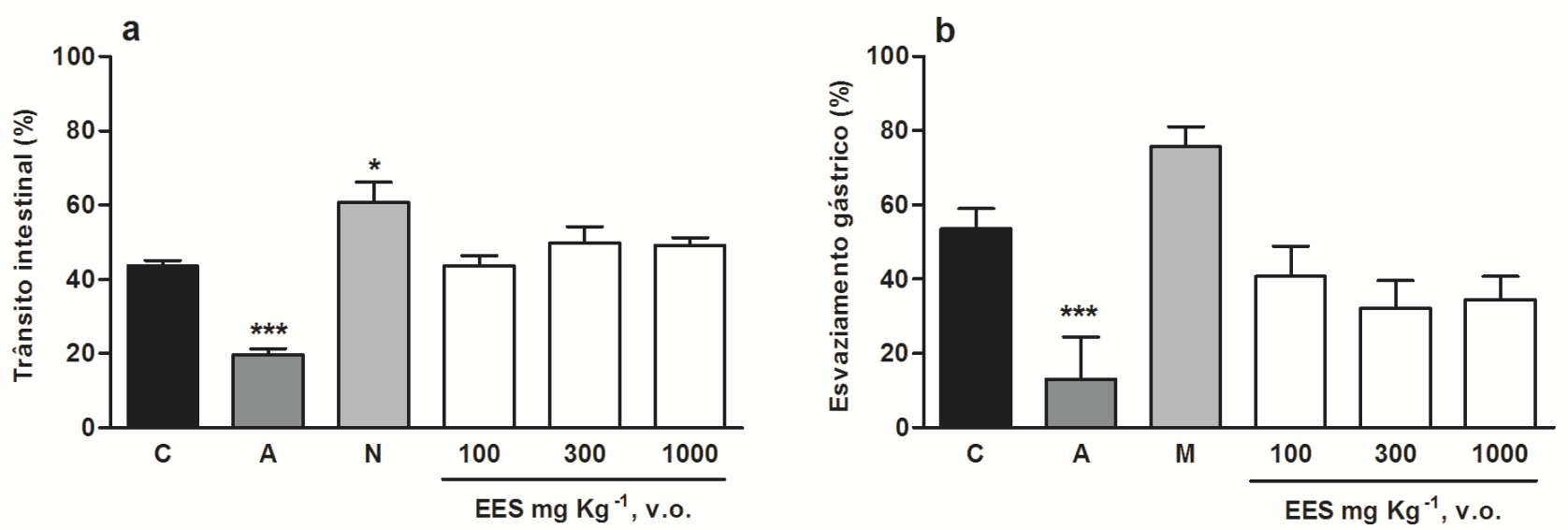

FIGURA 3. Efeito do extrato etanólico da Serjania erecta Radlk. no trânsito intestinal (a) e esvaziamento gástrico (b). Os animais receberam veículo ( $C$, água $0,1 \mathrm{~mL} / 10 \mathrm{~g}, \mathrm{v} .0)$, atropina $\left(A=3 \mathrm{mg} \mathrm{Kg}^{-1}, \mathrm{~s} . \mathrm{C}\right)$, neostigmina $(\mathrm{N}=$ $20 \mu \mathrm{g} \mathrm{Kg}^{-1}$, s.c), metoclopramida (30 mg Kg-1, v.o.) e EES (100, 300 e $1000 \mathrm{mg} \mathrm{Kg}^{-1}$, v.o.). Os resultados estão expressos como médias \pm erro padrão das médias $(n=7)$. A diferença entre os grupos foi determinada pela ANOVA de uma via seguida do teste de Bonferroni. * Diferente do grupo controle para $P<0,05$ e ${ }^{* *}$ para $P<0,001$. 
da Piper mollicomum aumentou apenas o trânsito intestinal, contudo esse aumento na motilidade gastrointestinal não foi dependente da dose. No entanto, o extrato bruto etanólico da Serjania erecta não promoveu nenhuma alteração na velocidade do trânsito intestinal e do esvaziamento gástrico, nas doses testadas. Com esses resultados podese sugerir que as plantas medicinais Persea major e Piper mollicomum apresentam princípios ativos capazes de alterar a motilidade gastrointestinal. Entretanto, mais estudos devem ser realizados para esclarecer os prováveis mecanismos de ação envolvidos no efeito pró-cinético do extrato dessas plantas. Dentre os principais moduladores que controlam a motilidade do TGI estão os neurotransmissores clássicos, como aceticolina e noradrenalina, além de outros transmissores como as substâncias não-adrenérgicas não-colinérgicas (óxido nítrico, serotonina, dopamina, entre outros) (Olsson \& Holmgren, 2001). Ainda, é de grande importância identificar quais os prováveis princípios ativos responsáveis pela atividade promovida pelos extratos.

Apesar do difundido uso etnofarmacológico dessas plantas medicinais para o tratamento de distúrbios gastrointestinais, é importante ressaltar que estudos tanto pré-clínicos quanto clínicos são imprescindíveis para a validação dos seus efeitos bem como a avaliação da toxicidade favorecendo o uso seguro por parte da população.

Com o conjunto de resultados podemos concluir que os extratos hidroalcoólicos de Persea major e Piper mollicomum podem ser tornar uma alternativa terapêutica para o tratamento de constipação ou de gastroparesias. No entanto, estudos adicionais precisam ser realizados para identificar os mecanismos de ação envolvidos.

\section{REFERÊNCIA}

ASSIS, L.N.S.P. et al. Avaliação da ação analgésica e antiedematogênica do extrato bruto de Persea major. In: CONGRESSO BRASILEIRO DE FARMACOLOGIA E TERAPÊUTICA EXPERIMENTAL, 35, 2003a, Águas de Lindóia. Anais... Águas de Lindóia: SBFTE, 2003.

ASSIS, L.N.S.P. et al. Propriedade antinociceptiva do extrato bruto hidroalcoólico de Persea major nas contorções abdominais induzidas por ácido acético. In: CONGRESSO BRASILEIRO DE FARMACOLOGIA E TERAPÊUTICA EXPERIMENTAL, 35, 2003b, Águas de Lindóia. Anais do XXXV Congresso Brasileiro de Farmacologia. Águas de Lindóia: SBFTE, 2003.
CALIXTO, J.B. Efficacy, safety, quality control, marketing and regulatory guidelines for herbal medicines (phytotherapeutic agents). Brazilian Journal of Medical and Biological Research, v.33, n.2, p.179189, 2000.

CALIXTO, J.B. Medicamentos fitoterápicos. In: YUNES, R.A.; CALIXTO, J.B. Plantas medicinais sob a ótica da química medicinal moderna. Chapecó. Ed. Argos, 2001.

CASTELO, A.P. et al. Gastroprotective effect of Serjania erecta Radlk (Sapindaceae): involvement of sensory neurons, endogenous nonprotein sulfhydryls, and nitric oxide. Journal of Medicinal Food, v.12, n.6, p.14111415, 2009.

COSMO, S.A. et al. Gastroprotective effect of hydroalcoholic extract from barks of Persea major Kopp (Lauraceae) in rats. Brazilian Journal of Pharmacognosy, v.17, n.4, p.533-537, 2007.

DE LIMA, M.R. et al. Anti-bacterial activity of some Brazilian medicinal plants. Journal of Ethnopharmacology, v.105, n.1-2, p.137-147, 2006.

DI STASI, L.C. et al. Screening in mice of some medicinal plants used for analgesic purposes in the state of Sao Paulo. Journal of Ethnopharmacology, v.24, n.2-3, p.205-211, 1988.

EKABO, O.A. et al. Antifungal and molluscicidal saponins from Serjania salzmanniana. Journal of Natural Products, v.59, n.4, p.431-435, 1996.

GOMIG, F. et al. Topical anti-inflammatory activity of Serjania erecta Radlk (Sapindaceae) extracts. Journal of Ethnopharmacology, v.118, n.2, p.220-224, 2008.

LAGO, J.H.G. et al. Antifungal derivatives from Piper mollicomum and $P$. Ihotzkyanum (Piperaceae). Quimica Nova, v.30, n.5, p.1222-1224, 2007.

LAPA, A.J. et al. Farmacologia e toxicologia de produtos naturais. In: SIMÕES, C.M.O.; SCHENKEL, E.P.; GOSMANN, G.; MELLO, J.C.P.D.; MENTZ, L.A.; PETROVICK, P.R. Farmacognosia: da planta ao medicamento. 2 ed. rev. Porto Alegre/Florianópolis, Ed. Universidade/UFRGS/Ed. da UFSC, 2000.

MARANHO, L.T. Contribuição ao estudo botânico, fitoquímico, farmacológico e microbiológico de Persea major Kopp (Lauraceae). 1998. 85p. Dissertação (Mestrado Botânica) - Universidade Federal do Paraná, Curitiba.

OLSSON, C.; HOLMGREN, S. The control of gut motility. Comparative Biochemistry and Physiology Part A, v.128, n.3, p.481-503, 2001.

PECKOLT, T.; PECKOLT, G. História das plantas medicinais e úteis do Brasil. Rio de Janeiro, Ed. Lemmert, 1888.

SANTOS, P.R. et al. Essential oil analysis of 10 Piperaceae species from the Brazilian Atlantic forest. Phytochemistry, v.58, n.4, p.547-551, 2001.

SUCHITRA, A.D. et al. Relative efficacy of some prokinetic drugs in morphine-induced gastrointestinal transit delay in mice. World Journal of Gastroenterology, v.9, n.4, p.779-783, 2003. 